\title{
Soft-computing approach to predict cost and performance of natural gas combined cycle (NGCC) plants using carbon dioxide capture
}

\author{
Udayan Singh $^{1} \cdot$ Naushita Sharma $^{1}$
}

Received: 9 June 2016/Accepted: 28 September 2016/Published online: 4 October 2016

(C) Indian National Academy of Engineering 2016

\begin{abstract}
Coal is the backbone of the Indian power sector with more than $60 \%$ of the net installed electricity capacity being coal-based. Among other fossil fuels, natural gas also contributes significantly to the power sector in India. This contribution may increase in the future with exploration of new reserves of unconventional gases, more stringent climate norms and so on. Concurrently, the global climate change problem also becomes more enhanced if larger dependence on fossil fuels remains. In some scenarios, carbon dioxide $\left(\mathrm{CO}_{2}\right)$ capture and storage (CCS) with natural gas combined cycle (NGCC) may be a feasible technological alternative. Such a scenario is manifested by some critical factors such as low natural gas prices and high carbon tax, among others. Nevertheless, several parameters remain highly uncertain if CCS is to be introduced in NGCC plants. As a result, modern computational techniques such as soft-computing approaches may be used to generate predictive models for cost and performance in such plants. This paper utilizes one such technique, multigene genetic programming (MGGP) to generate predictive models for cost of electricity (with coefficient of determination, $\left.\mathrm{R}^{2}>95 \%\right), \mathrm{CO}_{2}$ emission factor and net plant efficiency $\left(\mathrm{R}^{2}>98 \%\right)$. The sensitivity analysis carried out for these parameters show results which are expected in real situations. Subsequently, the calculation of the $\mathrm{CO}_{2}$ avoidance cost and energy penalty for a hypothetical case is demonstrated. The results show that MGGP can be successfully used in such applications.
\end{abstract}

Udayan Singh

udayansingh.1112@gmail.com

1 Department of Mechanical Engineering, National Institute of Technology Rourkela, Rourkela, India
Keywords NGCC · Genetic programming · Carbon capture and storage $\cdot$ Fossil fuel $\cdot$ Climate change

\section{Introduction}

India is heavily reliant upon coal for meeting its electricity demands, with more than $60 \%$ of its installed power capacity being coal based. However, a significant portion of the installed capacity $(\sim 8.5 \%)$ also comprises of natural gas fired power plants (CEA 2016). These plants, which work using combined cycle operation, provide cleaner electricity with less environmental impacts. However, because of India's low natural gas reserves, such power has never dominated the national scene.

The future electricity market in India may have a slightly larger role of natural gas, with the following considerations:

1. Natural gas prices in India have been steeply falling for the past few years because of the falling gas prices internationally. If such a decline continues, it may provide a slight boost to gas based power in India.

2. Post the Paris climate agreement, coal use in India and China has come under a lot of scrutiny. If international pressure rises, then natural gas may fill in the demands where renewable sources of electricity cannot be deployed.

3. Exploration for shale gas, coal-bed methane and underground coal gasification may help bridge the gas deficit in India.

4. Imported natural gas was used mostly as liquefied natural gas (LNG). However, with the inception of the Turkmenistan-Afghanistan-Pakistan-India (TAPI) pipeline, imported natural gas may also be utilized for power generation purposes. 
If natural gas comes to occupy a substantial chunk of the Indian power market in the future, then decarbonisation options associated with NGCC plants will have to be explored. This is so because Sathaye and Shukla (2013) have projected that there will be no single technology, which can play an overwhelming role in resolution of the climate change crisis. As a result, carbon dioxide $\left(\mathrm{CO}_{2}\right)$. capture in natural gas plants is an area which needs to be studied at least for techno-economic assessment. This area has not been explored by other researchers, since coal remains the single largest source of electricity in India. Thus, while many works have focussed on $\mathrm{CO}_{2}$ capture and storage (CCS) in coal-fired power plants (Karmakar and Kolar 2013; Rao and Kumar 2014; Singh and Rao $2014 \mathrm{a}$, b), none have estimated the cost of avoidance associated with carbon-dioxide capture and storage (CCS) in Indian NGCC plants.

In this paper, we initially simulate a natural gas combined cycle plant, based on current Indian financial parameters. Subsequently, the parameters are varied on hypothetical basis, but values are selected to be suitable in real plant conditions. On the basis of these realistic values, simulations are carried out to estimate the cost, emissions and performance of the plants. The system is then translated into a soft-computing domain using multi-gene genetic programming (MGGP) technique. The reader may refer to Garg et al. (2014a) for details on MGGP. Subsequently, parametric analysis is carried out and models for calculating the cost of $\mathrm{CO}_{2}$ avoidance are generated.

Implementing NGCC with CCS in India offers different challenges than elsewhere (say, USA, which has a greatly increasing shale gas reserve). A large volume of natural gas in India is imported and this trend is likely to increase in light to the inauguration of the TAPI pipeline. This renders the gas price to a high volatility. Also, O\&M costs in India are different, which have been compiled in Table 1 and included in this paper. Other parameters such as debt-equity ratio also vary depending on the country and legal framework.

\section{Context of this Paper}

The global climate change crisis has been identified as one of the major problems across the world. For countering this, our recent dependence on fossil fuels will have to decrease. However, unconventional sources of energy have not been developed in a cost-effective way so far to completely replace fossil fuels in the power sector. Thus, $\mathrm{CO}_{2}$ capture and storage (CCS) is commonly identified as a transition technology en-route to an energy mix with lower dependence on fossils (Maroto-Valer 2011).

India has a high degree of reliance on coal. This, coupled with the fact that coal based power plants have a higher $\mathrm{CO}_{2}$ emission factor (mass of $\mathrm{CO}_{2}$ emitted per unit of electricity generated), has meant that most of the research carried so far for CCS in India has been based on coal based power. Several works have identified the implications of CCS on the economics, costs, gaseous and particulate emissions, resource consumption and the overall energy sector of India. However, majority of these works (listed in Table 1) deal with coal based CCS on the capture front. Other works, of course pertain to source-sink matching and $\mathrm{CO}_{2}$ storage.

Garg et al. (2014b) utilized a multi-model comparison which looked at several conventional and rigorous strategies for greenhouse gas (GHG) abatement. They have concluded that in a carbon constrained scenario, natural gas based energy will play a considerable role in India due to its lower carbon content and because it can supply electricity during peak hours. Also, in some models such as the TIAM-ECN model and the WITCH model, the composition of CCS based power is higher for gas based plants than coal based plants, under specific scenarios. As a result, we need to understand the implications of $\mathrm{CO}_{2}$ capture on natural gas combined cycle (NGCC) plants in India.

Many international studies have studied how CCS would affect costs and performance of NGCC plants (Rubin et al. 2007; Rubin and Zhai 2012; Grande et al. 2009; Berstad et al. 2011). In India however, even if $\mathrm{CO}_{2}$ capture is integrated into NGCC plants, it will be met with a large degree of uncertainty in the parameters on account of being a new technology. Thus, this paper will develop predictive models to understand the functioning of NGCC plants with $\mathrm{CO}_{2}$ capture. It is also sought to understand if a soft-computing technique (viz, multi-gene genetic programming or MGGP, used in this paper) can suitably predict the cost and performance parameters and also represent the uncertainty encountered in such applications. The advantage of MGGP compared to other soft-computing techniques is its ability to generate predictive equations without assuming any prior relationship between the parameters (Kaydani et al. 2014). Thus, it helps in de-linking of the operating parameters which is of use to the present application, as shown in the sensitivity analysis in "Results and Discussion".

Many other researchers have also utilized soft-computing techniques such as fuzzy algorithms and neural networks to CCS based applications. Zhou et al. (2010) developed a neuro-fuzzy predictive model for predicting of $\mathrm{CO}_{2}$ production rate and other output parameters from four input parameters such as $\mathrm{CO}_{2}$ concentration in flue gas, steam flow rate, sorbent concentration and sorbent flow rate. They found out that such processes had an accuracy of greater than $90 \%$ for predicting the output. Zhou et al. (2011) compared neural network and neuro-fuzzy analysis for predicting $\mathrm{CO}_{2}$ capture process parameters. They suggested that the rule-base developed in neuro-fuzzy 
Table 1 Year-wise O\&M costs for the gas power plants in India

\begin{tabular}{|c|c|c|c|c|c|}
\hline Plant & Year & Net generation (MU) & O\&M cost (Rs in lakh) & $\mathrm{O} \& \mathrm{M}$ cost $(\mathrm{M} \$)^{\mathrm{a}}$ & O\&M (\$/MWh $)^{\mathrm{b}}$ \\
\hline \multirow[t]{5}{*}{ Anta } & 2008-2009 & 2456.19 & 6695.5 & 10.30 & 4.19 \\
\hline & 2009-2010 & 2933.49 & 6043.5 & 9.30 & 3.17 \\
\hline & 2010-2011 & 2420.77 & 7561.4 & 11.63 & 4.80 \\
\hline & 2011-2012 & 2420.77 & 6758.5 & 10.40 & 4.30 \\
\hline & 2012-2013 & 2125.08 & 9015.3 & 13.87 & 6.53 \\
\hline \multirow[t]{5}{*}{ Kawas } & 2008-2009 & 3429.6 & 9622.14 & 14.80 & 4.32 \\
\hline & 2009-2010 & 4253.5 & $10,218.7$ & 15.72 & 3.70 \\
\hline & 2010-2011 & 3808.5 & $11,385.18$ & 17.52 & 4.60 \\
\hline & 2011-2012 & 3540.6 & $11,042.4$ & 16.99 & 4.80 \\
\hline & 2012-2013 & 2839 & $12,918.67$ & 19.87 & 7.00 \\
\hline \multirow[t]{5}{*}{ Dadri gas } & 2008-2009 & 5153.9 & $13,525.39$ & 20.81 & 4.04 \\
\hline & 2009-2010 & 5475 & 9373.39 & 14.42 & 2.63 \\
\hline & 2010-2011 & 5271.2 & 9214.63 & 14.18 & 2.69 \\
\hline & 2011-2012 & 5247.1 & 9875.78 & 15.19 & 2.89 \\
\hline & 2012-2013 & 4311.6 & 9418.88 & 14.49 & 3.36 \\
\hline \multirow[t]{4}{*}{ Gandhar $^{\mathrm{c}}$} & 2009-2010 & 4423.7 & 9365.47 & 14.41 & 3.26 \\
\hline & 2010-2011 & 3990.3 & $10,605.95$ & 16.32 & 4.09 \\
\hline & 2011-2012 & 3618.9 & $12,710.18$ & 19.55 & 5.40 \\
\hline & 2012-2013 & 3414.3 & $10,666.38$ & 16.41 & 4.81 \\
\hline \multirow[t]{5}{*}{ Faridabad } & 2008-2009 & 2317.94 & 5753.25 & 8.85 & 3.82 \\
\hline & 2009-2010 & 3143.33 & 5144.91 & 7.92 & 2.52 \\
\hline & 2010-2011 & 3087.51 & 9323.05 & 14.34 & 4.64 \\
\hline & 2011-2012 & 3002.82 & $11,517.7$ & 17.72 & 5.90 \\
\hline & 2012-2013 & 1608.49 & 7250.93 & 11.16 & 6.94 \\
\hline
\end{tabular}

Source: CERC, http://www.cercind.gov.in/NTPC.html

${ }^{\text {a }}$ Using exchange rate of US\$ = Rs. 65

b $1 \mathrm{MU}=1000 \mathrm{MWh}$

c The O\&M cost for Gandhar plant was taken only for 4 years because the figure for the year 2008-2009 was abnormally high

technique can help in optimizing the process. Tan et al. (2010) developed crisp and fuzzy programming models in optimal planning of $\mathrm{CO}_{2}$ capture retrofitting in the power sector.

Several technical and financial factors are likely to affect the prospects of NGCC based CCS in India. Some of them include the plant load factor, type of capture technology, turbine inlet temperature etc. Another major instrument, which is likely to give CCS a push, is tax on $\mathrm{CO}_{2}$ (Shukla et al. 2010; Shukla and Chaturvedi 2013). The natural gas prices, which have been on a declining trend for some time, now, are also a crucial factor. Government of India released the New Domestic Natural Gas Pricing Guidelines which made the gas prices in India highly dependent on the natural gas pricing. This creates an inherent uncertainty in the gas pricing. Nevertheless, Shukla et al. (2009) have projected that at a price of less than US\$ 4/MBtu, gas compares favorably against coal as a base-load option.
The above factors are likely to result in a dynamic scenario, with wide ranging economic aspects of technologies and numerous operating parameters. Due to this, policymakers may desire a tool which accounts for uncertainty while also reducing estimation times. A modern soft-computing technique such as MGGP can result in meeting both these objectives. For instance, the equations and graphic results developed in "Results and Discussion" can help in calculating deviation in overall COE and efficiency, if operating parameters change by a certain degree. As a result, soft-computing techniques help in dual intertwined advantages for NGCC plants i.e. reduction in estimation times and accounting of uncertainty. Similar approaches using other intelligent techniques such as artificial neural networks (ANN) and multivariate regression analysis (MVRA) have been used in prediction of $\mathrm{CO}_{2}$ adsorption isotherms for Indian geologic formations (Verma and Sirvaiya 2016a, b). 


\section{Methodology}

The methodology for the above study involves four basic steps. The methodological framework for the study is shown in Fig. 1.

\section{Simulating a typical Indian NGCC plant}

Firstly, a typical NGCC plant in India is simulated using the cost assumptions for capital investments and average operation and maintenance (O\&M) costs. The simulation has been performed using the Integrated Environmental Control Model (IECM v8.0.2, https://www.cmu.edu/epp/ iecm/). The model offers a software framework to allow a multi-parameter, multi-output simulation of a power plant. Assumptions can be made with regards to various components of the power such as power block, turbine, fuel, general financing options and so on. The methodology followed in the model is sufficiently well-documented (Berkenpas et al. 1999) and we will not mention it here for the sake of brevity.

Most performance parameters at this stage are kept as IECM defaults. Using the estimates given in Indian Energy Security Scenarios (IESS) 2047 model (indiaenergy.gov.in/), the capital cost is estimated as Rs. $3586.5 / \mathrm{GW}$. The O\&M costs are found by taking the median of the O\&M costs of five running gas plants in India, viz. Anta, Kawas, Dadri, Gandhar and Faridabad (refer to Table 1). This leads us to a median O\&M cost of US\$ 4.24/MWh. The gas cost is taken as US\$ 4.2/MBtu (=US\$ $152.2 / \mathrm{mscm})$, representative of the current gas prices in India. The fuel escalation rate is taken as the median of the rates during April 2011 to October 2015, available from the website of the Central Electricity Regulatory Commission (CERC 2016) and calculated as $5.02 \%$. Other assumptions made in simulating the plant are shown in Table 2. Some of the assumptions stem either from the Government of India policy, such as the debt-equity ratio of 70:30 (Ministry of Power 2014) and has been considered in several other works as well (Singh and Rao 2015; Soni et al. 2016). Other assumptions have been taken in accordance with the industry norms (such as the gas turbine of GE 7FB make).

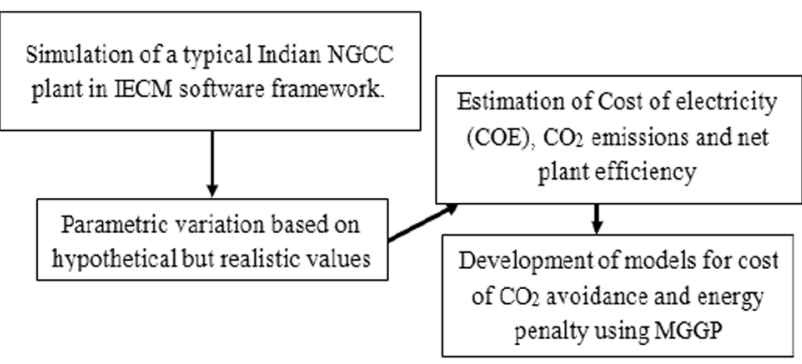

Fig. 1 Methodological framework for the study
Table 2 Assumptions used to simulate reference plant

\begin{tabular}{lll}
\hline Parameter & Unit & Value \\
\hline Plant life & Years & 30 \\
Real bond interest rate & $\%$ & 5.83 \\
Debt—equity ratio & Ratio & $70: 30$ \\
Gas properties & & \\
Methane $\left(\mathrm{CH}_{4}\right)$ & vol \% & 93.1 \\
Ethane $\left(\mathrm{C}_{2} \mathrm{H}_{6}\right)$ & vol \% & 3.2 \\
Propane $\left(\mathrm{C}_{3} \mathrm{H}_{8}\right)$ & vol \% & 1.1 \\
Carbon dioxide $\left(\mathrm{CO}_{2}\right)$ & vol \% & 1 \\
Nitrogen $\left(\mathrm{N}_{2}\right)$ & vol \% & 1.6 \\
Density & $\mathrm{kg} / \mathrm{m}^{3}$ & 0.76 \\
Gas turbine model & & $\mathrm{GE} 7 \mathrm{FB}$ \\
Turbine inlet temperature & $\mathrm{K}$ & 1644 \\
Turbine back pressure & $\mathrm{MPa}$ & $1.38 \times 10^{-2}$ \\
HRSG outlet temperature & $\mathrm{K}$ & 394 \\
\hline
\end{tabular}

Remaining parameters have been assumed as IECM defaults.

\section{Generating the dataset for MGGP}

After simulation of the reference plant, some key parameters are varied within the IECM v8.0.2 software framework to generate the basic dataset. In this process, $\mathrm{CO}_{2}$ capture is also incorporated within the dataset. The varied parameters take hypothetical but realistic values within the range of those parameters specified in the model. The range taken by each parameter is shown in Table 3 .

By varying the above parameters for 240 hypothetical cases, we obtain the outputs as cost of electricity, net plant efficiency and $\mathrm{CO}_{2}$ emission factor for each case. 180 sets of data are selected as training data and 60 as testing data. A sample dataset is shown in Table 4 for 50 sample sets of data.

\section{MGGP Approach}

Genetic programming (GP) is a mathematical tool that develops models or programs to solve regression problems (Garg et al. 2014a, c). The technique uses structure optimization method to search through the program space to provide solutions as a combination of multiple models or weighted sum of coefficients (Gandomi and Alavi 2012). Multi-gene genetic programming (MGGP) is a variant of GP where the output from a set of simple, fixeddepth GP models is used to produce a single program that develops a linear model culminating into a low-order nonlinear term (Garg et al. 2014a, c). This enables the mutation and crossover of a variety of multi-gene individuals. The methodology uses GPTIPS 2.0 toolbox 
Table 3 Ranges for variation of each parameter

\begin{tabular}{|c|c|c|c|}
\hline Parameter & Symbol & Unit & Range \\
\hline $\mathrm{CO}_{2}$ capture technology ${ }^{\mathrm{a}}$ & $a$ & & None/amine/ammonia \\
\hline Plant load factor* & $b$ & $\%$ & $25-80$ \\
\hline $\mathrm{CO}_{2} \operatorname{tax}$ & $c$ & $\$ / \mathrm{t}-\mathrm{CO}_{2}$ & $10-80$ \\
\hline Natural gas price & $d$ & $\$ / \mathrm{mscm}$ & $120-235$ \\
\hline Turbine inlet temperature & $e$ & $\mathrm{~K}$ & $1373-1713$ \\
\hline HRSG temperature & $f$ & $\mathrm{~K}$ & $353-413$ \\
\hline $\mathrm{CO}_{2}$ capture efficiency ${ }^{\mathrm{b}, * *}$ & $g$ & $\%$ & $50-90$ \\
\hline
\end{tabular}

* Plant load factor is an annual average value, which represents the percent of equivalent full load operation during a year (Berkenpas et al. 1999)

** $\mathrm{CO}_{2}$ capture efficiency indicates the percentage of the $\mathrm{CO}_{2}$ which the system is able to capture (Berkenpas et al. 1999)

a Since the variables in an MGGP expression can only take numerical values, therefore No Capture has been input as 0 , amine based capture as 1 and ammonia based capture as 2

b $\mathrm{CO}_{2}$ capture efficiency is always $0 \%$ when the $\mathrm{CO}_{2}$ capture technology assumes a value none or 0
(Searson 2015) for implementing MGGP that is independent of the interpretation of multi-gene individuals. The toolbox has two distinct modules for performing MGGP as well as multi-gene regression. The program uses high level crossover as a probabilistically selective substitute with a crossover rate parameter (CR) of 0.5 . This is termed as rate based high-level crossover where one or more genes are exchanged with any other selected individual. Additionally, the toolbox allows one to visualise the genes obtained by the model and facilitates the identification of those genes that can be further processed (either eliminated or modified) to reduce the complexity of the model. Table 5 shows the parameter setting used for MGGP approach in this study while Fig. 2 illustrates formulation of a multiple gene model resulting from a least mean square error algorithm.

\section{Results and Discussion}

A predictive model was developed for cost of electricity (COE), net plant efficiency and $\mathrm{CO}_{2}$ emission factor, with the parameters listed in Table 4 as input parameters. A high degree of correlation of more than $95 \%$ is noted between the predicted values and the actual values. The relative error (RE) for each case is calculated as less than $10 \%$ using the following formula:

$R E(\%)=\frac{R M S E}{\text { Average value }} \times 100$,

where RMSE or the root mean square error is given by (Garg et al. 2014c):

$R M S E=\sqrt{\frac{\sum_{i=1}^{N}\left|G_{i}-A_{i}\right|^{2}}{N}}$.
Here, $G_{i}$ is the predicted value for $i$ th data point generated using MGGP technique, $A_{i}$ is the actual value and $N$ is the number training samples. RMSE is selected as the critical parameter because it is defined as the fitness of a MGGP function in most cases (Muduli and Das 2014). Table 6 enlists the accuracy of the results obtained for each of the three output parameters.

The fitness function of the MGGP is used to determine which of the evolved expression best predicts the output parameter with minimum error. We will now see the correlation and sensitivity of each parameter towards the calculation of individual outputs.

\section{Results for Cost of Electricity}

Figure 3 shows the value of $1-\mathrm{R}^{2}$ against the increasing expressional complexity for the population model of COE. A total of 500 population models are generated. As we can see in the figure, most of the values correspond to a small value of $1-R^{2}$ and therefore an $R^{2}$ value of close to 1 . An expressional complexity of around 140 gives the best model, with the following equation:

$$
\begin{aligned}
C O E= & 0.8319 d-1.94 b-0.5572 a-0.05687 e-0.2654 f \\
& -0.08319 a c+0.02632 a f+1.578 a g \\
& +0.001963 d f-0.00005448 c g^{2}+0.00001013 d g^{2} \\
& +0.0002791 c(2 d+e-f+g)+0.01316 b^{2} \\
& -0.001963 g^{2}+0.0007475 a g(d-e) \\
& -0.005779 a b g+0.00002026 b c g+196.6
\end{aligned}
$$

The degree of correlation for the training and testing data, with respect to $\mathrm{COE}$ is shown in Fig. 4. Both display an $\mathrm{R}^{2}$ value of greater than $95 \%$, which is considerably high. 
Table 4 Sample inputs and outputs for dataset containing 50 hypothetical parametric values

\begin{tabular}{|c|c|c|c|c|c|c|c|c|c|c|}
\hline \multirow{2}{*}{$\begin{array}{l}\text { Sl. } \\
\text { no. }\end{array}$} & \multicolumn{7}{|c|}{ Input parameters } & \multicolumn{3}{|l|}{ Output } \\
\hline & $\begin{array}{l}\text { Capture } \\
\text { type }\end{array}$ & $\begin{array}{l}\text { Load } \\
\text { factor } \\
(\%)\end{array}$ & $\begin{array}{l}\mathrm{CO}_{2} \\
\operatorname{tax}(\$ / \\
\text { t) }\end{array}$ & $\begin{array}{l}\text { Natural gas } \\
\text { cost }(\$ / \\
\mathrm{mscm})\end{array}$ & $\begin{array}{l}\text { Turbine inlet } \\
\text { temperature } \\
(\mathrm{K})\end{array}$ & $\begin{array}{l}\text { HRSG } \\
\text { temperature } \\
(\mathrm{K})\end{array}$ & $\begin{array}{l}\text { Capture } \\
\text { efficiency } \\
(\%)\end{array}$ & $\begin{array}{l}\mathrm{COE} \\
(\$ / \\
\mathrm{MWh})\end{array}$ & $\begin{array}{l}\mathrm{CO}_{2} \text { emission } \\
\text { factor }(\mathrm{kg} / \mathrm{kWh})\end{array}$ & $\begin{array}{l}\text { Net plant } \\
\text { efficiency } \\
(\%)\end{array}$ \\
\hline 1 & Amine & 41 & 72 & 141 & 1137 & 145 & 71 & 141.6 & 0.13 & 39.99 \\
\hline 2 & None & 45 & 21 & 210 & 1361 & 112 & 0 & 105.1 & 0.36 & 50.53 \\
\hline 3 & Ammonia & 49 & 78 & 203 & 1376 & 108 & 71 & 154.6 & 0.12 & 42.85 \\
\hline 4 & Amine & 31 & 71 & 199 & 1380 & 148 & 64 & 155.6 & 0.15 & 44.51 \\
\hline 5 & Ammonia & 74 & 75 & 167 & 1225 & 143 & 85 & 145.4 & 0.08 & 36.16 \\
\hline 6 & Ammonia & 65 & 24 & 145 & 1230 & 132 & 87 & 137.4 & 0.06 & 36.34 \\
\hline 7 & Ammonia & 75 & 31 & 149 & 1169 & 143 & 87 & 144 & 0.07 & 34.09 \\
\hline 8 & Ammonia & 55 & 45 & 159 & 1324 & 137 & 84 & 141.2 & 0.08 & 38.8 \\
\hline 9 & Ammonia & 34 & 28 & 127 & 1140 & 157 & 84 & 216.9 & 0.09 & 33.22 \\
\hline 10 & None & 64 & 65 & 192 & 1228 & 85 & 0 & 110.3 & 0.36 & 50.18 \\
\hline 11 & Ammonia & 38 & 26 & 149 & 1140 & 99 & 65 & 173.3 & 0.16 & 40.09 \\
\hline 12 & Amine & 79 & 57 & 159 & 1373 & 121 & 84 & 96.03 & 0.07 & 43.92 \\
\hline 13 & None & 43 & 33 & 170 & 1102 & 86 & 0 & 107 & 0.38 & 48.55 \\
\hline 14 & None & 62 & 74 & 181 & 1387 & 101 & 0 & 106.1 & 0.36 & 51.08 \\
\hline 15 & Amine & 34 & 73 & 159 & 1202 & 132 & 66 & 151.1 & 0.15 & 42.27 \\
\hline 16 & Amine & 66 & 67 & 145 & 1379 & 120 & 90 & 95.52 & 0.04 & 43.54 \\
\hline 17 & Amine & 76 & 74 & 141 & 1386 & 97 & 62 & 91.37 & 0.15 & 46.36 \\
\hline 18 & None & 68 & 66 & 235 & 1262 & 106 & 0 & 125.3 & 0.36 & 49.78 \\
\hline 19 & Amine & 39 & 52 & 138 & 1382 & 139 & 80 & 114.8 & 0.08 & 43.75 \\
\hline 20 & None & 76 & 77 & 235 & 1123 & 85 & 0 & 132 & 0.37 & 48.9 \\
\hline 21 & None & 69 & 79 & 232 & 1348 & 96 & 0 & 124.8 & 0.36 & 50.92 \\
\hline 22 & Ammonia & 38 & 41 & 181 & 1192 & 154 & 81 & 209 & 0.10 & 35.63 \\
\hline 23 & Amine & 69 & 10 & 232 & 1181 & 145 & 74 & 142.1 & 0.12 & 40.73 \\
\hline 24 & Ammonia & 76 & 24 & 138 & 1293 & 104 & 88 & 113.9 & 0.06 & 38.78 \\
\hline 25 & None & 61 & 66 & 232 & 1216 & 85 & 0 & 126.3 & 0.36 & 50.05 \\
\hline 26 & Amine & 26 & 31 & 210 & 1365 & 124 & 80 & 169 & 0.08 & 44.02 \\
\hline 27 & Ammonia & 55 & 65 & 127 & 1348 & 119 & 62 & 116.7 & 0.16 & 43.24 \\
\hline 28 & Ammonia & 67 & 41 & 192 & 1260 & 145 & 73 & 147.6 & 0.12 & 39.08 \\
\hline 29 & Amine & 76 & 66 & 145 & 1216 & 142 & 81 & 103.5 & 0.08 & 40.99 \\
\hline 30 & Ammonia & 53 & 54 & 156 & 1357 & 148 & 72 & 135.1 & 0.12 & 40.85 \\
\hline 31 & Ammonia & 39 & 49 & 199 & 1321 & 111 & 71 & 172 & 0.12 & 41.94 \\
\hline 32 & Ammonia & 37 & 24 & 159 & 1231 & 135 & 75 & 178.7 & 0.12 & 38.61 \\
\hline 33 & Ammonia & 74 & 16 & 159 & 1286 & 125 & 63 & 114.1 & 0.16 & 41.94 \\
\hline 34 & Amine & 53 & 77 & 163 & 1176 & 132 & 66 & 130.2 & 0.15 & 41.77 \\
\hline 35 & Amine & 38 & 71 & 170 & 1211 & 140 & 81 & 148.7 & 0.08 & 40.98 \\
\hline 36 & None & 62 & 64 & 138 & 1266 & 87 & 0 & 90.25 & 0.36 & 50.49 \\
\hline 37 & None & 34 & 29 & 170 & 1253 & 88 & 0 & 104.8 & 0.36 & 50.32 \\
\hline 38 & None & 50 & 13 & 181 & 1256 & 131 & 0 & 94.45 & 0.37 & 48.81 \\
\hline 39 & Ammonia & 32 & 16 & 192 & 1303 & 130 & 65 & 184.4 & 0.15 & 41.71 \\
\hline 40 & None & 33 & 12 & 141 & 1123 & 139 & 0 & 96.55 & 0.39 & 46.54 \\
\hline 41 & Ammonia & 74 & 16 & 217 & 1136 & 128 & 85 & 179.9 & 0.08 & 34.38 \\
\hline 42 & Amine & 70 & 47 & 141 & 1159 & 80 & 64 & 100.8 & 0.15 & 43.83 \\
\hline 43 & Ammonia & 77 & 63 & 196 & 1316 & 140 & 81 & 141.4 & 0.08 & 39.06 \\
\hline 44 & None & 80 & 27 & 225 & 1389 & 141 & 0 & 103.2 & 0.36 & 49.87 \\
\hline 45 & Amine & 34 & 56 & 207 & 1109 & 111 & 61 & 169.5 & 0.17 & 41.66 \\
\hline 46 & Amine & 42 & 30 & 235 & 1206 & 88 & 60 & 155 & 0.16 & 44.54 \\
\hline
\end{tabular}


Table 4 continued

\begin{tabular}{|c|c|c|c|c|c|c|c|c|c|c|}
\hline \multirow{2}{*}{$\begin{array}{l}\text { Sl. } \\
\text { no. }\end{array}$} & \multicolumn{7}{|c|}{ Input parameters } & \multicolumn{3}{|l|}{ Output } \\
\hline & $\begin{array}{l}\text { Capture } \\
\text { type }\end{array}$ & $\begin{array}{l}\text { Load } \\
\text { factor } \\
(\%)\end{array}$ & $\begin{array}{l}\mathrm{CO}_{2} \\
\operatorname{tax}(\$ / \\
\mathrm{t})\end{array}$ & $\begin{array}{l}\text { Natural gas } \\
\text { cost }(\$ / \\
\mathrm{mscm})\end{array}$ & $\begin{array}{l}\text { Turbine inlet } \\
\text { temperature } \\
(\mathrm{K})\end{array}$ & $\begin{array}{l}\text { HRSG } \\
\text { temperature } \\
(\mathrm{K})\end{array}$ & $\begin{array}{l}\text { Capture } \\
\text { efficiency } \\
(\%)\end{array}$ & $\begin{array}{l}\mathrm{COE} \\
(\$ / \\
\mathrm{MWh})\end{array}$ & $\begin{array}{l}\mathrm{CO}_{2} \text { emission } \\
\text { factor }(\mathrm{kg} / \mathrm{kWh})\end{array}$ & $\begin{array}{l}\text { Net plant } \\
\text { efficiency } \\
(\%)\end{array}$ \\
\hline 47 & Amine & 26 & 43 & 174 & 1345 & 139 & 61 & 156.3 & 0.16 & 44.55 \\
\hline 48 & Amine & 52 & 34 & 207 & 1263 & 141 & 88 & 139.5 & 0.05 & 41.29 \\
\hline 49 & Ammonia & 58 & 46 & 130 & 1158 & 146 & 88 & 158 & 0.06 & 33.30 \\
\hline 50 & None & 43 & 17 & 141 & 1284 & 101 & 0 & 82.55 & 0.36 & 50.17 \\
\hline
\end{tabular}

Table 5 Parameter settings for MGGP used in GPTIPS 2.0 toolbox

\begin{tabular}{ll}
\hline Parameter & Value \\
\hline Population size & 250 \\
Number of generations & 150 \\
Number of runs & 2 \\
Maximum tree depth & 4 \\
Tournament size & 20 \\
Tournament type & Pareto \\
Elite fraction & 0.3 \\
\hline
\end{tabular}

Further, sensitivity analysis is performed for cost of electricity. In this process, two sets of data are taken. For the first set of data, each variable is increased by $10 \%$ one at a time, keeping other variables constant. For the second set, each variable is decreased by $10 \%$ one at a time, keeping other variables constant. It is found that the $\mathrm{COE}$ is most sensitive to turbine inlet temperature. Natural gas cost is the second most important parameter affecting the COE. On the other hand, $\mathrm{CO}_{2}$ tax and HRSG temperature are the parameters to which the $\mathrm{COE}$ is least sensitive to. It may be noted that although $\mathrm{CO}_{2}$ tax is a highly essential tool for controlling the large $\mathrm{CO}_{2}$ emissions, it does not show any major effect here because we are assuming the same capture technology in all the cases. As a result, the $\mathrm{CO}_{2}$ emission factor does not change considerably. The sensitivity analysis for COE is shown in Fig. 5.

The different degrees of sensitivity to capture efficiency in the two cases is seen because Case-I is a case of ammonia based capture at default capture efficiency of $65 \%$, while the second case represents amine based capture at capture efficiency of $80 \%$. The two solvents behave differently at different capture rates as shown in Fig. 6 with IECM simulations. It can be noted that the slope of COE
Fig. 2 Formulation of MGGP model using least squares algorithm (Garg et al. 2014c). Reproduced with permission

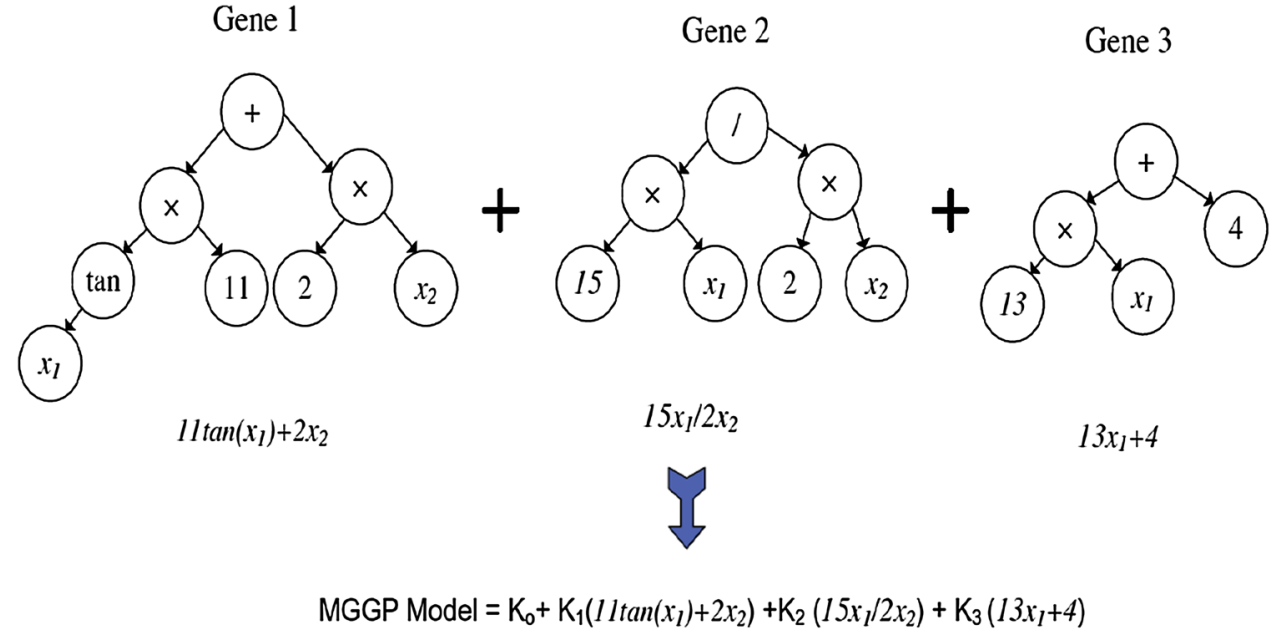

\begin{tabular}{llll}
\hline & $\mathrm{COE}$ & Net plant efficiency & $\mathrm{CO}_{2}$ emission factor \\
\hline Coefficient of determination, $\mathrm{R}^{2}$ & 0.9502 & 0.9944 & 0.9999 \\
Root mean square error & 7.2576 & 0.3480 & 0.0010 \\
Relative error (\%) & 5.44 & 0.79 & 0.51 \\
Mean absolute error & 4.0850 & 0.1322 & $6.85 \times 10^{-4}$ \\
Maximum absolute error & 34.5494 & 4.1891 & 0.0079
\end{tabular}

Table 6 Correlation and errors for each of the output parameters 
Fig. 3 Population models with varying expressional complexity. The red circle depicts the best model for $\mathrm{COE}$ (color figure online)

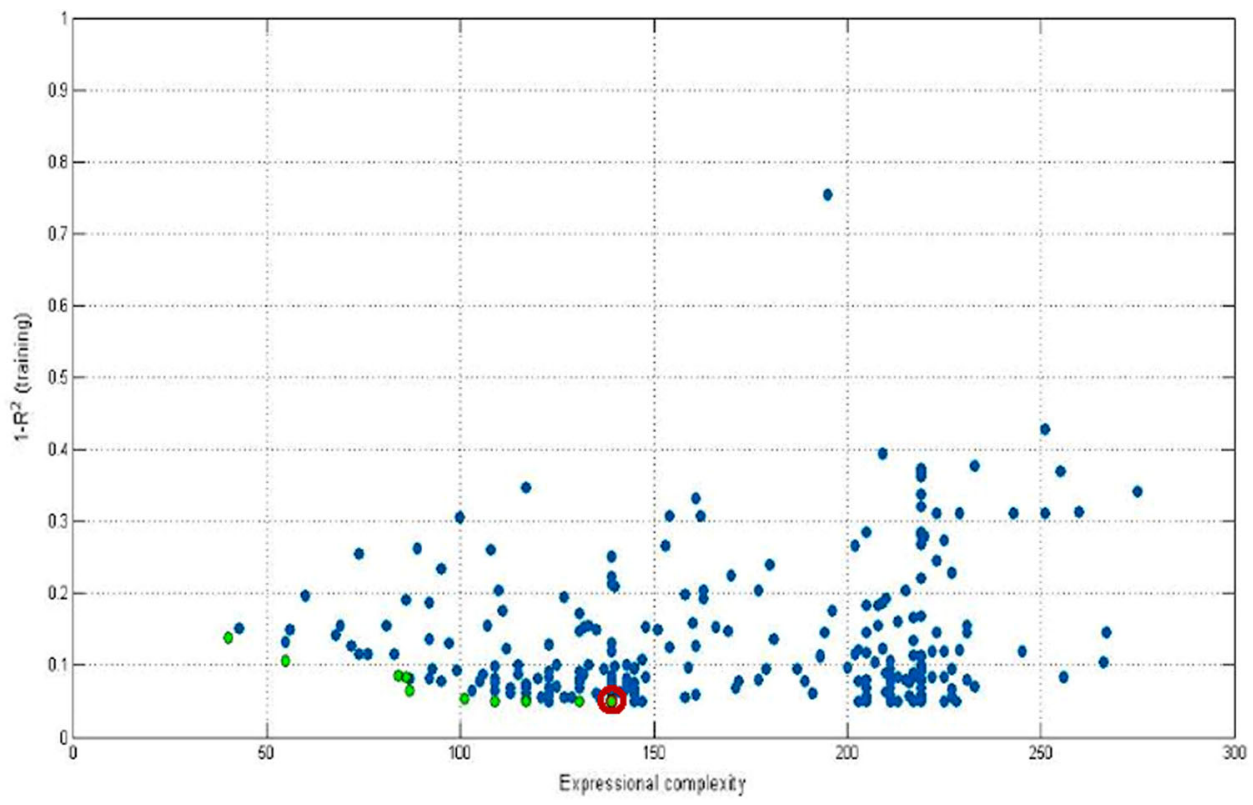

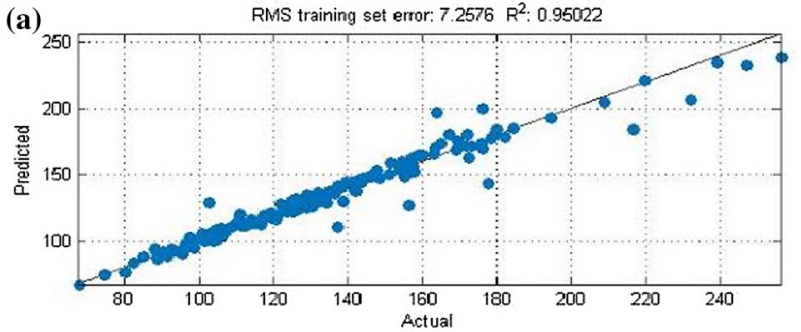

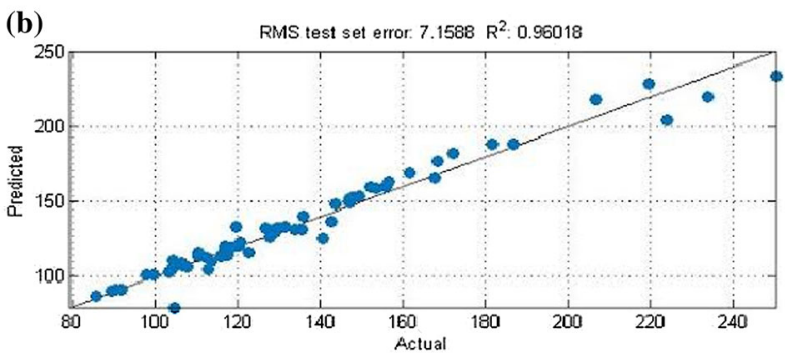

Fig. 4 Correlation of predicted value against the actual value of cost of electricity for a training data and $\mathbf{b}$ testing data

versus capture rate is significantly higher for ammonia based capture than amine based capture and as a result they show different levels of sensitivities to capture rate in Fig. 5.

\section{Results for Net Plant Efficiency}

For net plant efficiency, the population diagram is shown in Fig. 7. A larger number of points are seen with $\left(1-R^{2}\right)$ value close to 0 , as compared to the COE. The best fit is obtained for an expressional complexity of nearly 350 , with the following equation:
Net plant efficiency, $\eta=-0.00009888 a^{4} g^{2}-0.00000006814 a^{2} d f^{2}$

$-0.00000006814 b a^{2} d f-0.00106 a^{2} e+0.00009877 a e g$

$+0.4472 a-0.00000005627 d^{2} e-0.00000005627 d^{2} f$

$+0.02917 d-0.00002149 e^{2}-0.00002149 e g$

$+0.06729 e-0.03348 f-0.1574 g+0.0002296$.

The correlation between predicted and actual values of net plant efficiency is displayed in Fig. 8. The $\mathrm{R}^{2}$ value for both the training and testing sets of data is greater than $99.4 \%$, which shows a very high degree of correlation.

While a high $\mathrm{R}^{2}$ value gives a good indication of the ability of MGGP to predict the net plant efficiency, a major test relies upon its ability to perceive the parameters. MGGP, as an artificial intelligence technique, should be able to understand some critical factors, like; carbon tax should have no effect on the net plant efficiency. Whether this criterion is being satisfied by the model developed by us can be understood by carrying out sensitivity analysis. As in "Simulating a Typical Indian NGCC Plant", we vary each parameter by $10 \%$ one-by-one, keeping other parameters constant.

The results of the sensitivity analysis for net plant efficiency are shown in Fig. 9. It is quite evident that parameters such as $\mathrm{CO}_{2}$ tax, plant load factor and natural gas cost show no major effect on the plant efficiency. In fact, the percentage variation in efficiency due to $10 \%$ variation in $\mathrm{CO}_{2}$ tax is of the order $10^{-6} \%$, which is negligible. Thus, the model developed using MGGP not only shows a high $R^{2}$ value but is successful in identifying important input parameters affecting a particular output parameter. 
Fig. 5 Sensitivity analysis displayed as percentage change in $\mathrm{COE}$ due to $10 \%$ variation in input parameters
Fig. 6 Variation of cost of electricity with capture efficiency for amine and ammonia based capture
Case-I (Increase by 10\%)

- Case-II (Decrease by 10\%)
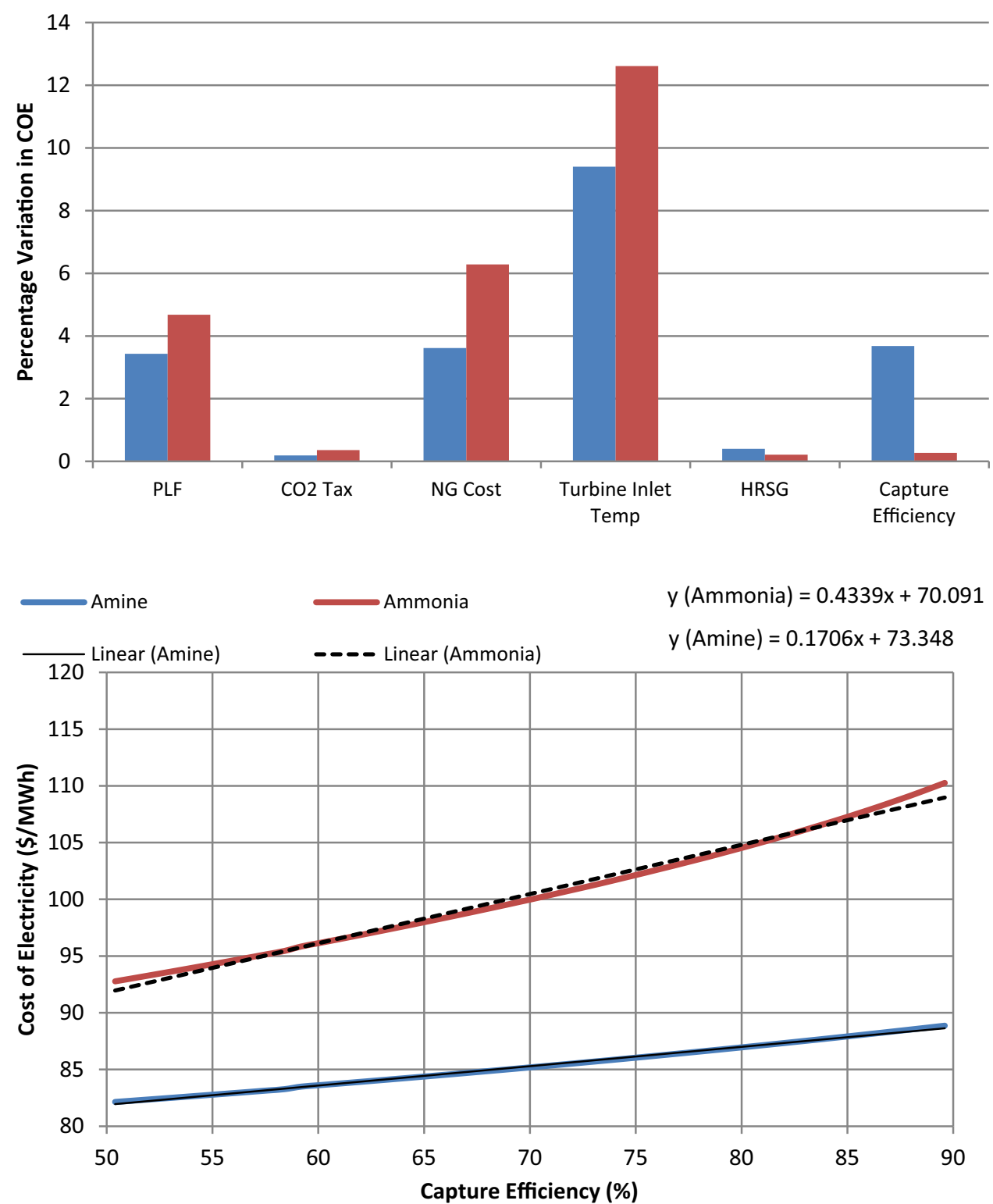

\section{Results for $\mathrm{CO}_{2}$ Emission Factor}

Similar results are obtained for $\mathrm{CO}_{2}$ emission factor using MGGP. The best fit model developed by the tool follows the equation,

$$
\begin{aligned}
& \mathrm{CO}_{2} \text { emission factor }=0.009785 a-0.0000009561 b \\
& +0.000003206 d-0.00004482 e+0.0007321 f \\
& \quad-0.003595 g-0.00002712 a e-0.00002712 a f \\
& -0.000003142 a g-0.0000003869 e f+0.0000009561 e g \\
& -0.000003142 f g+0.00000007179 a f^{2}-0.000008259 a^{2} g \\
& +0.009792 a^{2}+0.0000001305 f^{2}-0.000008259 g^{2} \\
& +0.0000000 a e f-0.0000003869 a f g+0.3954 .
\end{aligned}
$$

Figure 10 shows a high degree of correlation between the predicted values and the actual values for both training and testing data. The $\mathrm{R}^{2}$ value in both the cases is obtained to be greater than $98 \%$. The blue dots towards the right side of the curves depict the plants with no $\mathrm{CO}_{2}$ capture and those on the left represent plants with $\mathrm{CO}_{2}$ capture. Since, we have assumed that $\mathrm{CO}_{2}$ capture rate is always greater than $50 \%$, we find no data points in the middle of the curve.

The sensitivity analysis for $\mathrm{CO}_{2}$ emission factor is shown in Fig. 11. It is evident that capture efficiency, as expected, is the most dominant parameter affection the $\mathrm{CO}_{2}$ emission factor. Again, parameters like plant load factor do not affect the mass of $\mathrm{CO}_{2}$ emitted per unit 


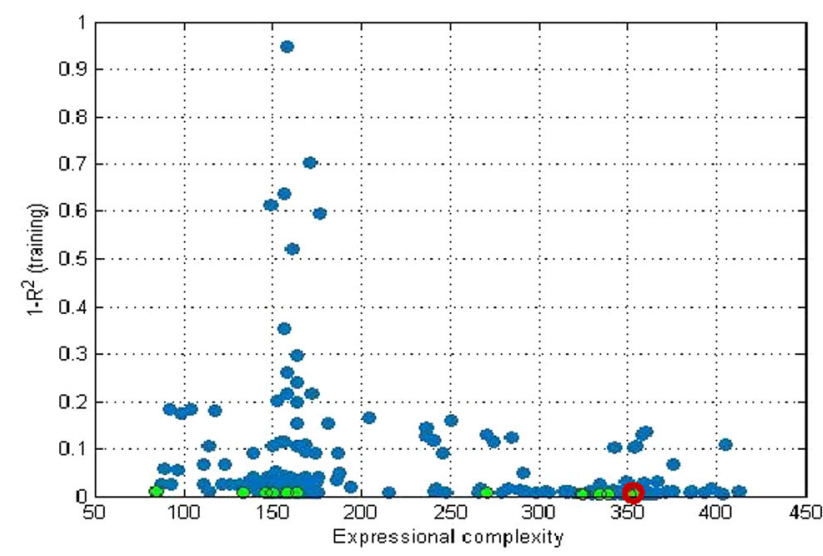

Fig. 7 Population models with varying expressional complexity. The red circle depicts the best model for net plant efficiency (color figure online)
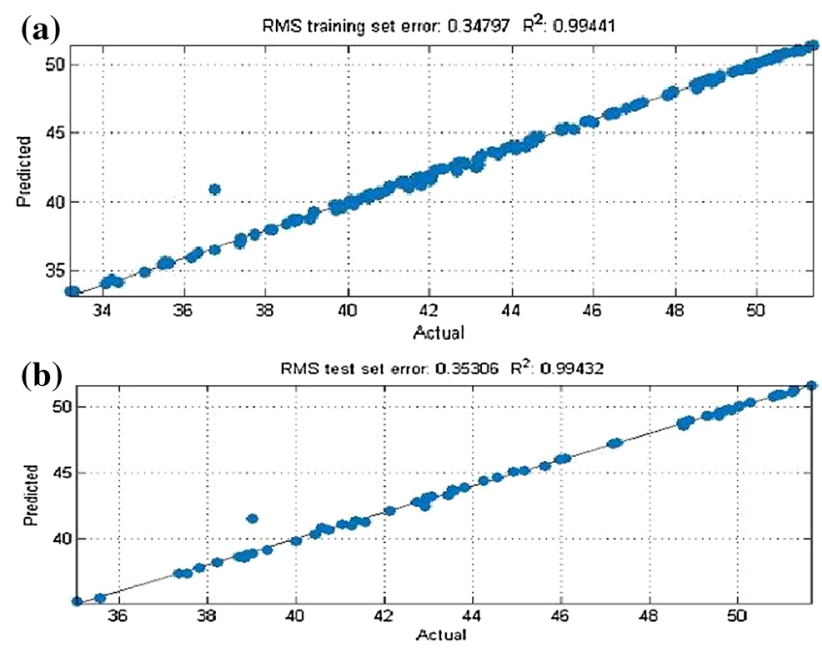

Fig. 8 Correlation of predicted value against the actual value of net plant efficiency for $\mathbf{a}$ training data and $\mathbf{b}$ testing data

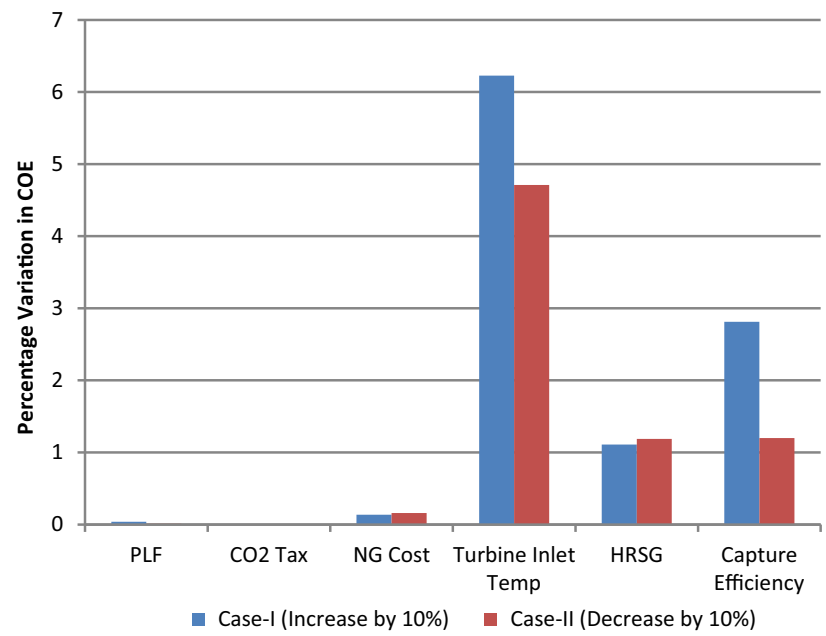

Fig. 9 Sensitivity analysis displayed as percentage change in net plant efficiency due to $10 \%$ variation in input parameters
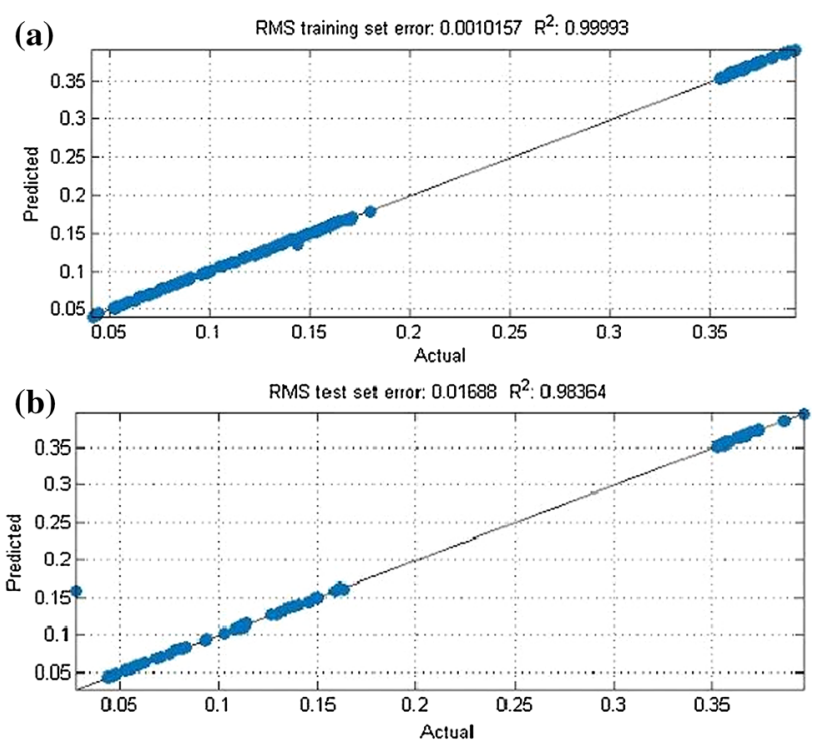

Fig. 10 Correlation of predicted value against the actual value of $\mathrm{CO}_{2}$ emission factor for $\mathbf{a}$ training data and $\mathbf{b}$ testing data

electricity generation. This is manifested well within the MGGP model. Thus, we can safely state that the models generated sufficiently match the expected results for all the three output parameters.

\section{Calculation of Cost of $\mathrm{CO}_{2}$ Avoidance and Energy Penalty}

The cost of $\mathrm{CO}_{2}$ avoidance is defined as the average cost of avoiding a unit mass of $\mathrm{CO}_{2}$ emissions to the atmosphere, while still generating the same amount of electricity (Rubin 2012). Mathematically,

Cost of $\mathrm{CO}_{2}$ avoidance $=\frac{C O E_{C C S}-C O E_{\text {ref }}}{E F_{r e f}-E F_{C C S}}$,

where $E F$ is the $\mathrm{CO}_{2}$ emission factor and the subscripts ref and $C C S$ denote the reference plant and the plant with CCS respectively.

Another major aspect of $\mathrm{CO}_{2}$ capture is that it decreases the net plant efficiency substantially, as it requires additional power to run the $\mathrm{CO}_{2}$ capture and compression equipment. The energy penalty represents the additional energy requirement to run a plant with $\mathrm{CO}_{2}$ capture and is given as (Rubin et al. 2007):

Energy penalty $=\frac{\eta_{\text {ref }}}{\eta_{C C S}}-1$,

where $\eta$ denotes the net plant efficiency and the subscripts ref and $C C S$ denote the reference plant and the plant with CCS respectively. 


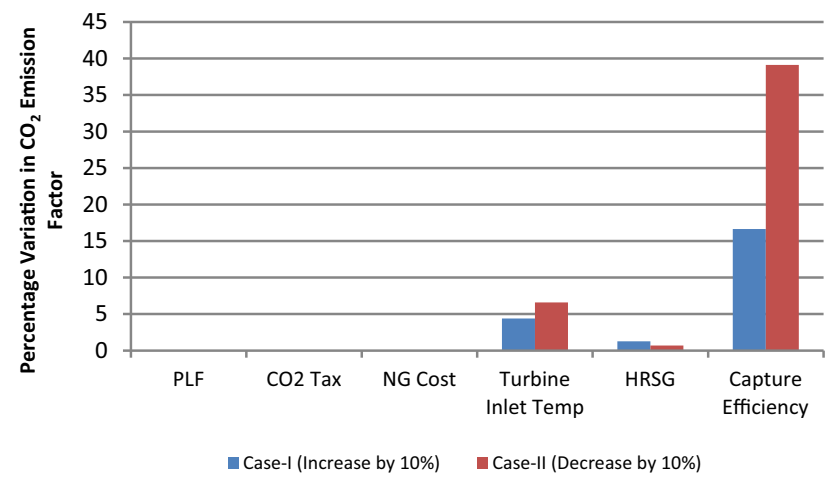

Fig. 11 Sensitivity analysis displayed as percentage change in $\mathrm{CO}_{2}$ emission factor due to $10 \%$ variation in input parameters

Table 7 Assumptions for S1 (high push) and S2 (low push) scenarios

\begin{tabular}{lrr}
\hline Parameter & \multicolumn{1}{c}{$\mathrm{S} 1$} & $\mathrm{~S} 2$ \\
\hline Plant load factor $(\%)$ & 75 & 30 \\
$\mathrm{CO}_{2}$ tax $\left(\$ / \mathrm{t}-\mathrm{CO}_{2}\right)$ & 65 & 15 \\
Natural gas price $(\$ / \mathrm{mscm})$ & 150 & 220 \\
Turbine inlet temperature $(\mathrm{K})$ & 1400 & 1100 \\
\hline
\end{tabular}

Table 8 Results for reference and CCS plants in the S1 (high push) and S2 (low push) scenarios

\begin{tabular}{|c|c|c|c|c|}
\hline & \multicolumn{2}{|l|}{ S1 } & \multicolumn{2}{|l|}{$\mathrm{S} 2$} \\
\hline & Ref & $\mathrm{CCS}$ & Ref & $\mathrm{CCS}$ \\
\hline Cost of electricity ( $\$ / M W h)$ & 84.73 & 88.03 & 130.82 & 190.73 \\
\hline Net plant efficiency $(\%)$ & 50.48 & 44.63 & 47.05 & 39.64 \\
\hline $\mathrm{CO}_{2}$ emission factor $(\mathrm{kg} / \mathrm{kWh})$ & 0.35 & 0.08 & 0.39 & 0.09 \\
\hline Cost of $\mathrm{CO}_{2}$ avoidance $\left(\$ / \mathrm{t}-\mathrm{CO}_{2}\right)$ & & 12.22 & & 199.7 \\
\hline Energy penalty $(\%)$ & & 13.11 & & 18.69 \\
\hline
\end{tabular}

Since, we have already developed models for COE, net plant efficiency and emission factor in "Results for Cost of Electricity", "Results for Net Plant Efficiency" and "Results for $\mathrm{CO}_{2}$ Emission Factor", we can easily replace the values in the aforementioned equations to calculate the cost of $\mathrm{CO}_{2}$ avoidance and the energy penalty. For this, we assume two cases, a high push scenario favourable to CCS (S1) and low push (S2), with the assumptions as shown in Table 7. Both scenarios assume amine based capture at a capture efficiency of $80 \%$.

The results for the two scenarios are shown in Table 8 .

Thus, the results obtained for the two scenarios match the expected results i.e. the high push scenario shows a lower cost of $\mathrm{CO}_{2}$ avoidance and energy penalty. Using the equation in "Results for Cost of Electricity" for COE and varying the values for various parameters as shown in Table 7, we arrive at the results shown in Table 8. In fact, keeping other parameters in the $\mathrm{S} 1$ scenario same and changing the $\mathrm{CO}_{2}$ tax to US\$80/t-CO cost of avoidance becomes zero. In other words, at this rate, CCS in the natural gas power plants becomes financially and environmentally feasible. This is so because the cost of electricity with CCS becomes less than that without CCS, thereby increasing the incentives to use the technology.

\section{Conclusion}

In this paper, we began by discussing why $\mathrm{CO}_{2}$ capture and storage (CCS) in the natural gas based power sector could be seen as a favourable alternative. Nonetheless, considerable uncertainties exist in the various important parameters affecting this technology. As a result, predictive models can be developed to predict cost and performance of such power plants, which may be further refined and used as the uncertainties decrease. The present paper has utilized one particular technique, namely, multi-gene genetic programming (MGGP) to generate predictive models for cost of electricity, $\mathrm{CO}_{2}$ emission factor and the net plant efficiency. It was found that the $\mathrm{R}^{2}$ value for cost of electricity is greater than $95 \%$, while for the other two parameters it is substantially higher than $98 \%$, thereby showing a considerably high correlation. The sensitivity analysis carried out on such models also show expected results. Lastly, we have created two hypothetical scenarios to calculate the cost of $\mathrm{CO}_{2}$ avoidance and energy penalty for the CCS process and the results follow the expected trend. It is also observed that at typical operating ranges and a natural gas price of around US\$ 4/MBtu, a carbon tax of US\$ 80/t-CO $\mathrm{CO}_{2}$ makes CCS in the NGCC power plants a viable option.

Acknowledgments The authors gratefully acknowledge the IECM team at Carnegie Mellon University, USA and the GPTIPS 2.0 team for making the tool publicly available. They also thank Prof. S.S. Mahapatra, Head, Department of Mechanical Engineering, NIT Rourkela, for his skilful guidance.

\section{References}

Berkenpas MB, Frey HC, Fry JJ, Kalagnanam J, Rubin ES (1999) Integrated environmental control model technical documentation. Center for Energy and Environmental Studies, Carnegie Mellon University, Pittsburgh

Berstad D, Arasto A, Jordal K, Haugen G (2011) Parametric study and benchmarking of NGCC, coal and biomass power cycles integrated with MEA-based post-combustion $\mathrm{CO}_{2}$ capture. Energy Procedia 4:1737-1744

CEA (2016) All India Installed Capacity (in MW) of power stations as on 30.04.2016. http://www.cea.nic.in/reports/monthly/instal ledcapacity/2016/installed_capacity-04.pdf. Accessed 9 June 2016 
CERC (2016) Central electricity regulatory commission. http://www. cercind.gov.in/ Accessed 9 June 2016

Gandomi AH, Alavi AH (2012) A new multi-gene genetic programming approach to non-linear system modeling. Part II: geotechnical and earthquake engineering problems. Neural Comput Appl 21:189-201

Garg A, Garg A, Tai K (2014a) A multi-gene genetic programming model for estimating stress-dependent soil water retention curves. Comput Geosci 18:45-56

Garg A, Shukla PR, Kankal B et al (2014b) Low climate impact scenarios and the implications of required tight emission control strategies. Indian Institute of Management, Ahmedabad

Garg A, Vijayaraghavan V, Mahapatra SS, Tai K, Wong CH (2014c) Performance evaluation of microbial fuel cell by artificial intelligence methods. Expert Syst Appl 41(4):1389-1399

Grande CA, Ribeiro RP, Rodrigues AE (2009) $\mathrm{CO}_{2}$ capture from NGCC power stations using electric swing adsorption (ESA). Energy Fuels 23:2797-2803

Karmakar S, Kolar AK (2013) Thermodynamic analysis of high-ash coal-fired power plant with carbon dioxide capture. Int J Energ Res 37:522-534

Kaydani H, Mohebbi A, Eftekhari M (2014) Permeability estimation in heterogeneous oil reservoirs by multi-gene genetic programming algorithm. J Petrol Sci Eng 123:201-206

Maroto-Valer MM (2011) Why carbon capture and storage? Greenhouse Gases Sci Technol 1:3-4

Muduli PK, Das SK (2014) CPT-based seismic liquefaction potential evaluation using multi-gene genetic programming approach. Indian Geotech J 44:86-93

Rao AB, Kumar P (2014) Cost implications of carbon capture and storage for the coal power plants in India. Energy Procedia $54: 431-438$

Rubin ES (2012) Understanding the pitfalls of CCS cost estimates. Int J Greenhouse Gas Control 10:181-190

Rubin ES, Zhai H (2012) The cost of carbon capture and storage for natural gas combined cycle power plants. Environ Sci Technol 46:3076-3084

Rubin ES, Chen C, Rao AB (2007) Cost and performance of fossil fuel power plants with $\mathrm{CO}_{2}$ capture and storage. Energy Policy 35:4444-4454

Sathaye J, Shukla PR (2013) Methods and models for costing carbon mitigation. Annu Rev Environ Resour 38:137-168
Searson DP (2015) GPTIPS 2: an open-source software platform for symbolic data mining. In: Handbook of genetic programming applications. Springer International Publishing, pp 551-573

Shukla PR, Chaturvedi V (2013) Sustainable energy transformations in India under climate policy. Sustain Dev 21:48-59

Shukla PR, Dhar S, Victor DG, Jackson M (2009) Assessment of demand for natural gas from the electricity sector in India. Energy Policy 37:3520-3534

Shukla PR, Dhar S, Fujino J (2010) Renewable energy and low carbon economy transition in India. J Renew Sustain Energy 2:031005

Singh U, Rao AB (2014a) Estimating the environmental implications of implementing carbon capture and storage in Indian coal power plants. In: 2014 international conference on advances in energy research. IEEE, pp 226-232

Singh U, Rao AB (2014b) Prospects of carbon capture and storage (CCS) for new coal power plants in India. In: Proceedings of the 1st national conference on advances in thermal engineering. ISM Dhanbad, pp 165-174

Singh U, Rao $\mathrm{AB}$ (2015) Integrating $\mathrm{SO}_{2}$ and $\mathrm{NO}_{\mathrm{x}}$ control systems in Indian coal-fired power plants. Decision 42:191-209

Soni V, Singh SP, Banwet DK (2016) Sustainable coal consumption and energy production in India using life cycle costing and real options analysis. Sustain Prod Consum 6:26-37

Tan RR, Ng DK, Foo DC, Aviso KB (2010) Crisp and fuzzy integer programming models for optimal carbon sequestration retrofit in the power sector. Chem Eng Res Des 88:1580-1588

Verma AK, Sirvaiya A (2016a) Intelligent prediction of Langmuir isotherms of Gondwana coals in India. J Petrol Explor Prod Technol 6:135-143

Verma AK, Sirvaiya A (2016b) Comparative analysis of intelligent models for prediction of Langmuir constants for $\mathrm{CO}_{2}$ adsorption of Gondwana coals in India. Geomech Geophys Geo-Energy Geo-Resour 2:97-109

Zhou Q, Chan CW, Tontiwachwuthikul P (2010) An application of neuro-fuzzy technology for analysis of the $\mathrm{CO}_{2}$ capture process. Fuzzy Sets Syst 161:2597-2611

Zhou Q, Wu Y, Chan CW, Tontiwachwuthikul P (2011) Modeling of the carbon dioxide capture process system using machine intelligence approaches. Eng Appl Artif Intell 24:673-685 